\title{
Contribution of Outer Membrane Porin (Omp) K36 to Klebsiella pneumoniae induced Liver Abscess \\ Junn-Liang Chang ${ }^{1,2}$, Wen-Cheng Tsai ${ }^{3}$ and Jiun-Han Chen ${ }^{4^{*}}$ \\ ${ }^{1}$ Department of Pathology and Laboratory Medicine, Taoyuan Armed Forces General Hospital, Taoyuan City, Taiwan, \\ ${ }^{2}$ Biomedical Engineering Department, Ming Chuan University, Taoyuan City, Taiwan \\ ${ }^{3}$ Department of Medicine, Zuoying Branch of Kaohsiung Armed Forces General Hospital, Kaohsiung City, Taiwan \\ ${ }^{4}$ Department of Medical Laboratory Science and Biotechnology, Yuanpei University of Medical Technology, Hsinchu, Taiwan
}

\begin{abstract}
Introduction: Pyogenic liver abscess is usually caused by multiple bacterial infections. This disease can be caused by single microorganism, Klebsiella pneumoniae that has been reported in Asia, North America and Europe. Many virulence factors of K. pneumoniae have identified including capsular polysaccharide, lipopolysaccharide, serum resistance, adhesins and siderophores. Previously, we demonstrated the virulent effect of outer membrane porin (OMP) K 36 by a lethality study. However, the role of OmpK36 in liver abscess pathogenesis is still unclear.
\end{abstract}

Objective: In this study, a virulent K. pneumoniae strain NVT-1002 and OmpK36 deficient mutant ( $\triangle \mathrm{OMPK})$ were used to examine the contribution of OmpK36 to liver abscess. Liver injuries and inflammatory cytokines expression were detected by tissue section and enzyme linked-immunosorbent assay respectively. The toxic effect of OmpK36 to human hepatoma cell (HepG2) was tested by bacterial infections and the treatment with OmpK36 recombinant protein.

Results: The Results demonstrated that the NVT-1002 induced sever liver injuries while little or no damage was found in mice injected with OmpK36. Expression of serum and liver cytokines including TNF- $\alpha$, IL- $1 \beta$, IL- 6 and IL-10 were elevated after injection of NVT-1002, meanwhile, only IL-1 $\beta$ was transiently elevated in OmpK36 group. Interestingly, OmpK36 recombinant protein showed no toxic effect to HepG2 cells, and the virulence of OmpK36 mutant to HepG2 was not altered compared to NVT-1002 group.

Conclusion: In conclusion, OmpK36 contributes to the K. pneumoniae induced liver abscess and inflammatory responses. The virulent effect of OmpK36 is not mediated by the protein itself, but other uncertain mechanisms. OmpK36 may be a therapeutic target in K. pneumoniae infection.

\section{Introduction}

Klebsiella pneumoniae have been documented as the common factor for cryptogenic liver abscess in Asia Pacific [1,2]. Similar findings in North America and Europe have also been reported [35]. Several virulent factors of $K$. pneumoniae were discovered and these factors are almost related to specific capsular polysaccharides (CPS) [2,6-8]. Accumulating reports have indicated that the capsule is essential to the virulence of Klebsiella species [9-11]. Up to now, the capsular antigen have been classified into 77 serotypes, and serotype $\mathrm{K} 1$ and $\mathrm{K} 2$ capsular antigen were found to comprise virulence in mouse peritonitis model, whereas isolates of serotypes other than K1 or K2 were with little or no virulence [5,12].

Outer membrane porins (OMP) are proteins that cross a cellular membrane and contribute to the diffusion of molecules. Many studies have showed OMPs play important roles in antimicrobial resistance $[13,14]$. Previously, we have demonstrated the virulent effects of OMPK 36 by an animal study [15]. In this report, the results of animal lethality study showed that the virulence of OmpK36 mutant was reduced about 100 fold compared to the wild-type strain NVT1002, which was isolated from a patient with liver abscess. However, the participation of OmpK36 in K. pneumoniae induced liver abscess formation and the toxicity to cells are still unclear. In this study, we examined the role of OmpK36 in K. pneumoniae induced pathogenesis by animal model and the inflammatory cytokines were also detected. In addition, the direct toxic effects of OmpK36 and whole bacteria were detected by the cell model.

\section{Materials and Methods}

\section{Mice liver abscess study} (H\&E) staining.

\section{Publication History:}

Received: August 26, 2016

Accepted: September 29, 2016

Published: October 01, 2016

\section{Keywords:}

OmpK36, Virulence, Liver abscess, Inflammatory

Klebsiella pneumoniae isolates NVT-1002 and $\Delta \mathrm{OmpK} 36$ were obtained as previously [15]. The adult BALB/c mice were injected intraperitoneally with $103 \mathrm{cfu}$ of $K$. pneumoniae NVT-1002 or $\Delta$ OmpK36-NVT-1002 in $0.1 \mathrm{~mL}$ phosphate buffered saline. Mice were sacrificed with $\mathrm{CO} 2$ after 1-3 days bacterial injections, the livers were removed, fixed with paraformaldehyde and embedded in paraffin. Histological sections were observed after hematoxylin-eosin

\section{Kinetic of inflammatory cytokines production in liver and serum}

Liver was removed for tissue section and supernatant of each sample was collected for cytokines production. Cardiac blood samples were collected under aseptic conditions. Blood samples were allowed to colt at $40^{\circ} \mathrm{C}$ and then centrifuged at $15000 \mathrm{rpm}$ for $3 \mathrm{~min}$. Serum samples "Corresponding Author: Prof. Jiun-Han Chen, Department of Medical Laboratory Science and Biotechnology, Yuanpei University of Medical Technology, Hsinchu, Taiwan, 306, Yuanpei Street, Hsinchu, Taiwan; E-mail: jhchen@mail.ypu.edu.tw

Citation: Chang JL, Tsai WC, Chen JH (2016) Contribution of Outer Membrane Porin (Omp) K36 to Klebsiella pneumoniae induced Liver Abscess. Int J Clin Med Microbiol 1: 112. doi: https://doi.org/10.15344/2456-4028/2016/112

Copyright: (๑ 2016 Chang et al. This is an open-access article distributed under the terms of the Creative Commons Attribution License, which permits unrestricted use, distribution, and reproduction in any medium, provided the original author and source are credited. 
Citation: Chang JL, Tsai WC, Chen JH (2016) Contribution of Outer Membrane Porin (Omp) K36 to Klebsiella pneumoniae induced Liver Abscess. Int J Clin Med Microbiol 1: 112. doi: https://doi.org/10.15344/2456-4028/2016/112

Page 2 of 5

were preserved at $-80^{\circ} \mathrm{C}$ until measurement of the cytokine. Cytokine concentrations in liver and serum were measured with a mice cytokine 10-plex antibody bead kit (R\&D systems, Minneapolis, MN) according to the manufacturer's instructions. Tumor necrosis factor (TNF)- $\alpha$, interleukin (IL)-1 $\beta$, IL- 6 and IL-10 levels were determined. The supernatants from homogenized liver were then withdrawn at the indicated times, and dilutions were assayed in triplicate for each independent experiment. All samples were tested in triplicate. The minimal detectable protein concentration was $10 \mathrm{pg} / \mathrm{ml}$.

\section{Construction of pET30a-OmpK36}

The DNA fragment of OmpK36 was amplified by primer pairs OmpK36F (5'-GGGAATTCCATATGCACCATCATCATCATCATA TGAAAGTTAAAGTACTG-3') and OmpK36R (5'-CCGCTCGAG GAACTGGTAAACCAGGCC-3') from a clinical isolate NVT-1002. The amplified fragments were digested with restriction enzymes and cloned into the expression region of plasmid pET30a (Novagen). The pET30a-OmpK36 was used to express a 6 His-OmpK36 protein as described below.

\section{Recombinant OmpK36 protein expression, purification and detoxification}

The pET30a-OmpK36 was transformed into BL-21 (DE3) competent cells. An overnight cell culture $(3 \mathrm{~mL})$ was grown at $37^{\circ} \mathrm{C}$ in the presence of $50 \mathrm{mg} / \mathrm{L}$ kanamycin. After transfer of the cell culture to $300 \mathrm{ml}$ of Luria-Bertani medium, the cell suspension was allowed to reach an OD600 of $0.7-0.9$ before addition of IPTG $(1 \mathrm{mM})$. Cells were grown for $4 \mathrm{~h}$ at $37^{\circ} \mathrm{C}$ and then centrifuged at $9000 \mathrm{~g}$ for $30 \mathrm{~min}$. Whole-cell lysates were prepared by sonication (Sonics Vibracell sonicator, 25\% amplitude, pulsed $1 \mathrm{sec}$ "on" and $2 \mathrm{sec}$ "off" for a total of 5 min of "on" time, at $4 \mathrm{sec}$ ) in phosphate buffered saline with $6 \mathrm{M}$ urea. The soluble protein fraction was then mixed with $8 \mathrm{~mL}$ of $\mathrm{Ni}^{2+}$ resins (Amersham) to capture the His-OmpK36 recombinant protein. The $\mathrm{Ni}^{2+}$ resins was then washed with $40 \mathrm{~mL}$ of wash buffer $(10 \mathrm{mM}$ imidazole, $6 \mathrm{M}$ urea, $10 \%$ glycerol in phosphate buffered saline (PBS)) and eluted by wash buffer with $40 \mathrm{mM}$ imidazole. The flowthrough was collected and dialyzed by PBS with $3 \mathrm{M}$ urea and $10 \%$ glycerol for $4 \mathrm{hr}$ and then by PBS with 10\% glycerol overnight. The endotoxin was removed by Pierce Detoxi-Gel endotoxin removal gel (Thermo Scientific, Rockford, IL) as described in user's manual. Expression of the His-OmpK36 protein was determined Western blot and the final protein concentration was measured by Bradford assay (Bio-Rad).

\section{Culture of hepatoma HepG2 cells}

HepG2 cells was cultured in Eagle's Minimum Essential Medium supplemented with $10 \%$ fetal bovine serum (FBS), incubated at $37^{\circ} \mathrm{C}, 5 \% \mathrm{CO}_{2}$ in a humidified incubator. The culture medium will be changed every day. Cells were grown to confluence in $25 \mathrm{~cm} 2$ tissue flasks. Subsequently, the cells was trypsinized with trypsin/ EDTA solution in phosphate-buffered saline (PBS), centrifuged and resuspended in fresh media. Before the experiment, cells were seeded onto the variant tissue culture dishes overnight.

\section{Cell viability assay}

Cell viability was detected by MTS assay, Cell titer $96^{\circ}$ AQueus (Promega). In brief, $2 \times 10^{4}$ cells were seeded on to 48 well plates in $200 \mu \mathrm{l}$ serum free media per well and incubated for $24 \mathrm{hrs}$. After variant treatments included of a multiplicity of infection (MOI) of 60 whole bacterial infection or OmpK36 recombinant protein, cells were washed with PBS 3 times, $20 \mu \mathrm{l}$ MTS reagents were added to each well in the final volume of $100 \mu \mathrm{l}$ and placed in incubator for 2 hours. The optical density was measured at $490 \mathrm{~nm}$ using a plate reader.

\section{Statistical analysis}

Student's $\mathrm{t}$ test was used for statistical analysis. Data represented as means \pm standard deviations. P values of less than 0.05 was considered statistically significant.

\section{Results}

Contribution of OmpK36 the K. pneumoniae induced liver abscess

Histological sections showed that remarkable injuries in liver were seen after 24 hours of injection with wild type K. pneumoniae (NVT1002). More severe injuries were found at day 2 and day 3 (Figure 1). In the meanwhile, the injuries were almost abolished in mice injected with OmpK36-KO. This is suggested that OmpK36 plays an important role in K. pneumoniae induced liver abscess (Figure 1).

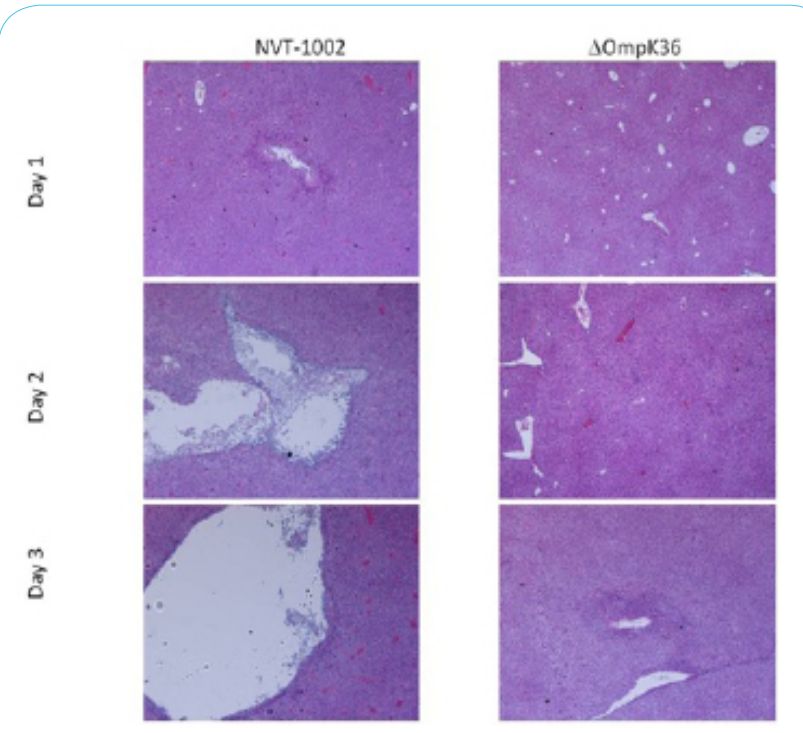

Figure 1: Contribution of OmpK36 to the pathogenesis of liver abscess. The wild-type NVT-1002 can induce the tissue damage in liver significantly and with a time dependent manner. The phenomena was almost abolished in OmpK36 deficient mutant (Magnification, $\times 100$ ).

Rols of OmpK36 in Klebsiella pneumoniae induced cytokines expression, included of TNF- $\alpha$, IL-1 $\beta$, IL- 6 and IL-10

Pro- and anti-inflammatory cytokines secretion in response to bacterial infection included IL-1 $\beta$, IL- 6 , IL-10 and TNF- $\alpha$ were detected by ELISA. The wild-type K. pneumoniae NVT-1002 elicited the secretions of all the cytokines both in plasma (Figure 2) and liver (Figure 3). It is notable that most of the elevated cytokines have the peaks at day 2 . In contrast, the OmpK $36 \mathrm{KO}$ mutant only transiently enhanced IL-1ßexpressions and the other cytokines were almost undetectable both in liver and serum.

Direct cytotoxic effects of OmpK36 recombinant protein and whole bacterial infection to HepG2 hepatoma cells 
Citation: Chang JL, Tsai WC, Chen JH (2016) Contribution of Outer Membrane Porin (Omp) K36 to Klebsiella pneumoniae induced Liver Abscess. Int J Clin Med Microbiol 1: 112. doi: https://doi.org/10.15344/2456-4028/2016/112

Page 3 of 5

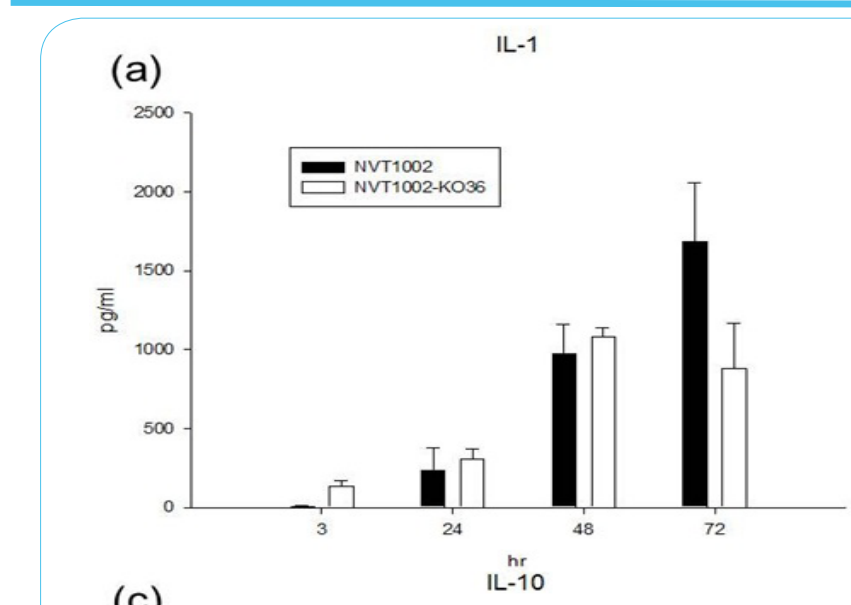

(c)
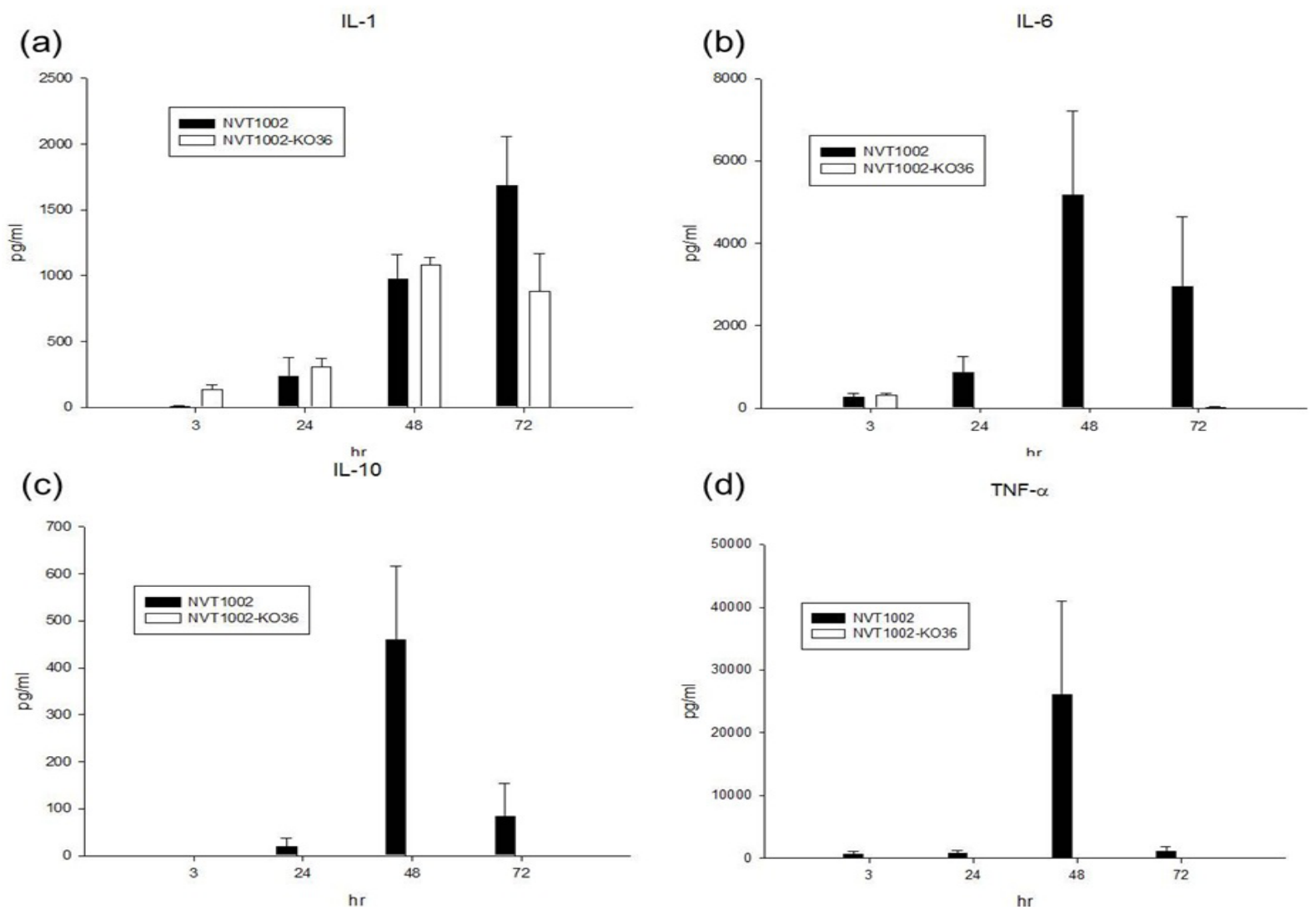

(d)

TNF- $\alpha$

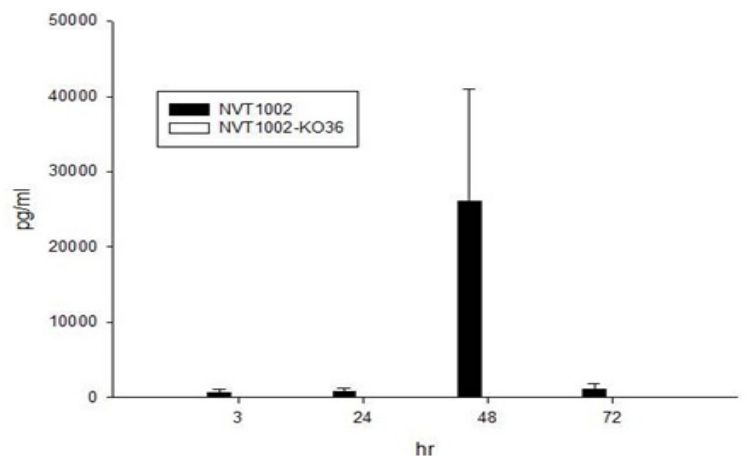

Figure 2: Role of OmpK36 in serum cytokines TNF- $\alpha$, IL-1 $\beta$, IL- 6 and IL-10 secretion. The wild-type NVT-1002 can elevate the serum cytokines significantly including TNF- $\alpha$, IL-1 $\beta$, IL- 6 and IL- 10 , while the $\Delta$ OmpK36 can only enhance IL-1 $\beta$ expression. The value was mean \pm standard error of mean (SEM) at 3, 24, 48 and 72 hours of reaction, $n=5$.
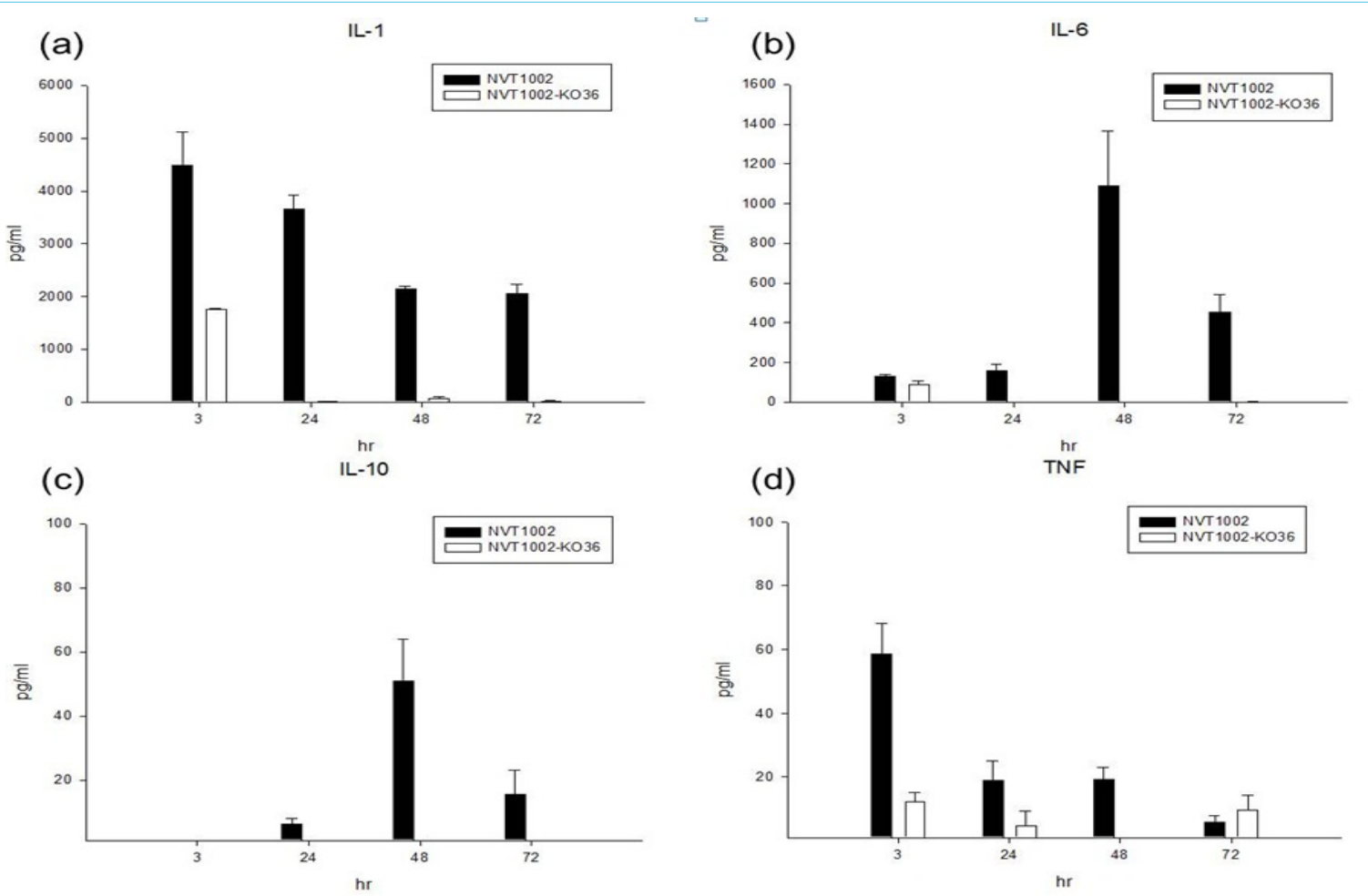

Figure 3. Role of OmpK36 in hepatic cytokines TNF- $\alpha$, IL-1 $\beta$, IL-6 and IL-10 secretion. The wild-type NVT-1002 can elevate the hepatic cytokines significantly including TNF- $\alpha$, IL- $1 \beta$, IL- 6 and IL-10, while the $\Delta$ OmpK36 can only enhance IL- $1 \beta$ expression. The value was mean \pm standard error of mean (SEM) at 3, 24, 48 and 72 hours of reaction, $n=5$. 
HepG2 hepatoma cells were incubated with various concentrations of OmpK36recombinant protein for 24 hours or infected with whole bacteria with a MOI of 60 for 2-6 hours. The viability of HepG2 cells were then detected by MTS. Results showed that no significant difference was detected in the toxicity to HepG2 cells (Figure 4a). Similar results were found in the toxicity of whole bacterial infection, the cell viability was not altered in the $\Delta \mathrm{OmpK} 36$ group compared to the NVT-1002 group (Figure 4b). demonstrated that high IL-10 / TNF- $\alpha$ ratio is associated with the mortality [30]. In this study, the serum TNF- $\alpha$, IL-6 and IL-10 were elevated and have the peaks at day 2 after injection of wild type NVT1002 (Figure 2). Similar results were found in hepatic IL-6 and IL10 (Fig. 3). At the time point, sever injuries were observed in tissue sections (Figure 1). It is possible that the expressions of cytokines are associated with the pathogenesis of liver abscess. In the OmpK36 deficient group, both serum and hepatic IL-1 $\beta$ were elevated, the other (a)

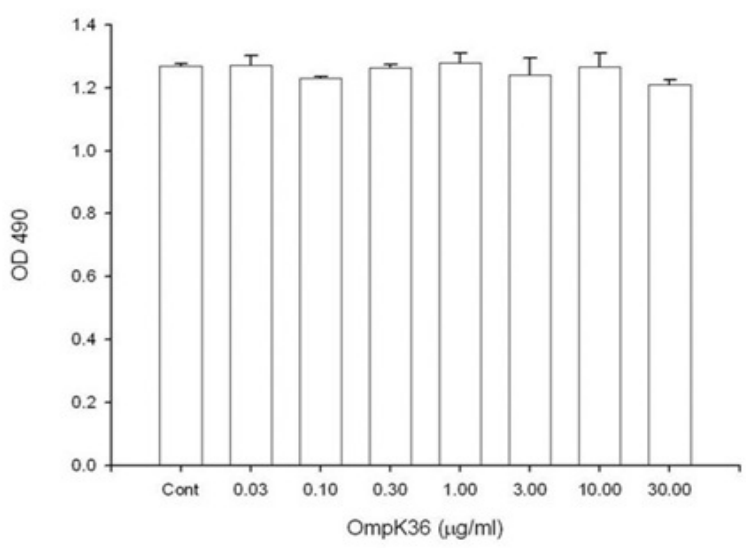

(b)

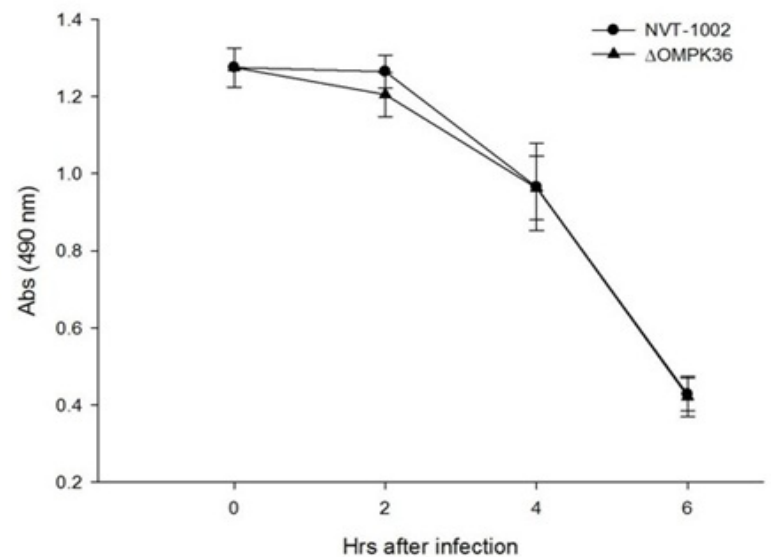

Figure 4. Direct cytotoxicity effect of OmpK36 and whole bacteria (NVT-1002 and $\Delta$ OmpK36) in hepatoma cells HepG2. HepG2 cells were treated with (a) variant concentrations of recombinant OmpK36 for 24 hours and (b) bacteria NVT-1002 or $\Delta$ OmpK36. Viability was detected by MTS method. There was no significant difference in cell viability. The value was mean \pm standard error of mean (SEM), $n=5$.

\section{Discussion}

Liver abscesses caused by K. pneumoniae were first reported in Taiwan [1,16]. The extra-hepatic complications spread by blood stream such as endophthalmitis, fasciitis and meningitis have been reported [1,17-19]. The syndrome was subsequently reported in Asia and America $[20,21]$. To date, the syndrome is emerging world wildly [22]. Several virulent factors of K. pneumoniae were described, including lipopolysaccharide, capsular polysaccharide, siderophore, resistance to phagocytosis and serum killing [23]. K. pneumoniae strains expressing capsular type $\mathrm{K} 1$ or $\mathrm{K} 2$ antigen are especially virulent. [7,24]. Previously, we first demonstrated that OmpK36 is a virulent factor of $K$. pneumoniae. However, the involvement of this porin in $K$. penumoniae induced liver abscess progression is still unclear. The wild-type NVT-1002 used in this study is a serotype K1 clinical isolate which was isolated from patient with liver abscess. Injection with NVT-1002 intraperitoneally can induce severe hepatic injuries in experimental mice (Figure 1). On the contrary, the injuries were almost abolished in OmpK36 KO mutant group (Figure 1). Although this model cannot simulate the disease completely, it is still suggested that OmpK36 plays an important role in the pathogenesis of K. pneumoniae induced liver abscess.

Endogenous TNF-ais associated with severity of hemorrhagic and thrombotic lesions in organs, especially in the liver and kidney $[25,26]$. IL- 6 and IL-10 have the potential to inhibit TNF- $\alpha$ and IL- $\beta$ expression from macrophage and peripheral monocytes [27, 28]. IL-6 also has the anti-inflammatory potential by activation of transcription-3 protein in hepatocytes [27]. The balance of the inflammatory and anti-inflammatory cytokines may determine the tissue damage and mortality [29]. A previous report has been cytokines were almost undetectable (Figure 2 and Figure 3). This is evident that $\mathrm{OmpK} 36$ participate in the $\mathrm{K}$. pneumoniae induced immune responses. However, the detail cellular and molecular mechanisms need further studies.

To identify the toxic effect of OmpK36, the in vitro cell model was used in this study. The HepG2 cells were treated with various concentrations of OmpK 36 and the cell viability was detected by MTS method. Unexpectedly, the viability of HepG2 cells was not affected by recombinant OmpK36 protein (Figure 4a). Results of whole bacterial toxicity to HepG2 also showed that there is no significant difference was observed (Figure 4b). This is suggested that OmpK36 has no direct toxic effect to HepG 2 cells. Previous study has been demonstrated that OmpK36 contributes to the resistance to phagocytosis, serum killing and the bacterial clearance in hepatocytes [15]. OmpK36 might prolong the duration of bacterial burden subsequently enlarge the injuries in organs such as liver and kidney.

The OmpK36 KO mutant used in this study should be with intact lipopolysaccharide and capsule. At least, the process of knock out is not affecting any target genes about LPS or capsule. Since the toxic effect is not from OmpK36 itself, another putative mechanism is that the expression of OmpK36 may influence the structure of other virulent factors such as LPS and capsule [31-33], the surface inflammatory inducer(s). However, the detail molecular mechanisms need more evidences.

In brief, OmpK36 contributes to the virulence of K. pneumoniae. The protein participates in the pathogenesis of K. pneumoniae induced liver abscess. The toxic effect of OmpK36 is mediated by enhancing other virulent factors possibly. The molecular mechanism(s) need further studies. 
Citation: Chang JL, Tsai WC, Chen JH (2016) Contribution of Outer Membrane Porin (Omp) K36 to Klebsiella pneumoniae induced Liver Abscess. Int J Clin Med Microbiol 1: 112. doi: https://doi.org/10.15344/2456-4028/2016/112

Page 5 of 5

\section{Competing Interests}

The authors declare that they have no competing interests.

\section{Funding}

This work was supported by grants from Zuoying Branch of Kaohsiung Armed Forces General Hospital (ZBH 102-02), Yuanpei University (101-COMP6011-10, 100-COMP6012-01), Taoyuan Armed Forces General Hospital (102-27).

\section{References}

1. Liu YC, Cheng DL, Lin CL (1986) Klebsiella pneumoniae liver abscess associated with septic endophthalmitis. Arch Intern Med 146: 1913-1916.

2. Yeh KM, Kurup A, Siu LK, Koh YL, Fung CP, et al.,(2007) Capsular serotype $\mathrm{K} 1$ or $\mathrm{K} 2$, rather than magA and $\mathrm{rmpA}$, is a major virulence determinan for Klebsiella pneumoniae liver abscess in Singapore and Taiwan. J Clin Microbiol 45: 466-471.

3. Fang FC, Sandler N, Libby SJ (2005) Liver abscess caused by magA+ Klebsiella pneumoniae in North America. J Clin Microbiol 43: 991-992.

4. Karama EM, Willermain F, Janssens X, Claus M, Van den Wijngaert S, et al., (2008) Endogenous endophthalmitis complicating Klebsiella pneumoniae liver abscess in Europe: case report. Int Ophthalmol 28: 111-113.

5. Keynan Y, Karlowsky JA, Walus T, Rubinstein E (2007) Pyogenic live abscess caused by hypermucoviscous Klebsiella pneumoniae. Scand $J$ Infect Dis 39: 828-830.

6. Cheng KS, Tang HL, Hsu CH, Lai HC, Yu CJ, et al. (2007) A clinical survey of Klebsiella pneumoniae virulence and genotype in pyogenic liver abscess. Adv Ther 24: 589-593.

7. Lin JC, Chang FY, Fung CP, Xu JZ, Cheng HP, et al., High prevalence of phagocytic-resistant capsular serotypes of Klebsiella pneumoniae in liver abscess. Microbes Infect 6: 1191-1198.

8. Yeh KM, Chang FY, Fung CP, Lin JC, Siu LK, et al., (2006) magA is no a specific virulence gene for Klebsiella pneumoniae strains causing liver abscess but is part of the capsular polysaccharide gene cluster of $\mathrm{K}$ pneumoniae serotype K1. J Med Microbiol 55: 803-804.

9. S J Cryz Jr, Fürer F, Germanier R (1984) Experimental Klebsiella pneumoniae burn wound sepsis: role of capsular polysaccharide. Infect Immun 43: 440-441.

10. Domenico P, Johanson WG Jr, Straus DC (1982) Lobar pneumonia in rats produced by clinical isolates of Klebsiella pneumoniae. Infect Immun 37: 327-335

11. Highsmith AK, Jarvis WR (1985) Klebsiella pneumoniae: selected virulence factors that contribute to pathogenicity. Infect Control 6: 75-77.

12. Mizuta K, Ohta M, Mori M, Hasegawa T, Nakashima I, et al. (1983) Virulence for mice of Klebsiella strains belonging to the 01 group: relationship to their capsular (K) types. Infect Immun 40: 56-61.

13. Hernández-Allés S1, Conejo Md, Pascual A, Tomás JM, Benedí VJ, et al. (2000) Relationship between outer membrane alterations and susceptibility to antimicrobial agents in isogenic strains of Klebsiella pneumoniae. Antimicrob Chemother 46: 273-277.

14. Martínez-Martínez L, Pascual A, Hernández-Allés S, Alvarez-Díaz D, Suárez Al, et al., (1994) Roles of beta-lactamases and porins in activities of carbapenems and cephalosporins against Klebsiella pneumoniae. Antimicrob Agents Chemother 43: 1669-1673.

15. Chen JH, Siu LK, Fung CP, Lin JC, Yeh KM, et al. (2010) Contribution of outer membrane protein $\mathrm{K} 36$ to antimicrobial resistance and virulence in Klebsiella pneumoniae. J Antimicrob Chemother 65: 986-990.

16. Yang CC, Yen CH, Ho MW, Wang JH (1995) Comparison of pyogenic liver abscesses caused by Klebsiella pneumoniae and non-K. pneumoniae pathogens. J Formos Med Assoc 94: 232-237.

17. Saccente, M (2006) Klebsiella pneumoniae liver abscess, endophthalmitis and meningitis in a man with newly recognized diabetes mellitus. Clin Infect Dis 29: 1570-1571.

18. Hu BS, Lau YJ, Shi ZY, Lin YH (1999) Necrotizing fasciitis associated with Klebsiella pneumoniae liver abscess. Clin Infect Dis 29: 1360-1361.
19. Cheng HP, Siu LK, Chang FY (2003) Extended-spectrum cephalosporin compared to cefazolin for treatment of Klebsiella pneumoniae-caused liver abscess. Antimicrob Agents Chemother 47: 2088-2092.

20. Rahimian J, Wilson T, Oram V, Holzman RS (2004) Pyogenic liver abscess: recent trends in etiology and mortality. Clin Infect Dis 39: 1654-1659.

21. Pastagia M, Arumugam V (2008) Klebsiella pneumoniae liver abscesses in a public hospital in Queens, New York. Travel Med Infect Dis 6: 228-233.

22. Struve C, Bojer M, Nielsen EM, Hansen DS, Krogfelt KA, et al., (2005) Investigation of the putative virulence gene magA in a worldwide collection of 495 Klebsiella isolates: magA is restricted to the gene cluster of Klebsiella pneumoniae capsule serotype K1. J Med Microbiol 54: 1111-1113.

23. Podschun R, Ullmann U (1998) Klebsiella spp. as nosocomial pathogens: epidemiology, taxonomy, typing methods, and pathogenicity factors. Clin Microbiol Rev 11: 589-603.

24. Yeh KM, Chiu SK, Lin CL, Huang LY, Tsai YK, et al., (2016) Surface antigens contribute differently to the pathophysiological features in serotype K1 and K2 Klebsiella pneumoniae strains isolated from liver abscesses. Gut Pathog 8: 4.

25. Nakajima Y,Momotani E, Takahashi H, Ishikawa $\mathrm{Y}$, Ito T, et al., Endogenous tumor necrosis factor (TNF) production and modification of pathological lesions in experimental Escherichia coli endotoxemia of piglets. Vet Immunol Immunopathol, 45: 45-54.

26. Nakajima Y, Mikami O, Yoshioka M, Arai S, Miura K, et al. (2000) Involvement of apoptosis in the endotoxemic lesions of the liver and kidneys of piglets. $\mathrm{J}$ Vet Med Sci 62: 621-626.

27. Teoh N, Field J, Farrell G (2006) Interleukin-6 is a key mediator of the hepatoprotective and pro-proliferative effects of ischaemic preconditioning in mice. J Hepatol 45: 20-27.

28. Armstrong L, Millar AB (1997) Relative production of tumour necrosis factor alpha and interleukin 10 in adult respiratory distress syndrome. Thorax 52: 442-446.

29. Charavaryamath C, Janardhan KS, Caldwell S, Singh B (2006) Pulmonary intravascular monocytes/macrophages in a rat model of sepsis. Anat $\operatorname{Rec} A$ Discov Mol Cell Evol Biol 288: 1259-1271.

30. Gogos CA, Drosou E, Bassaris HP, Skoutelis A (2000) Pro- versus antiinflammatory cytokine profile in patients with severe sepsis: a marker for prognosis and future therapeutic options. J Infect Dis 181: 176-180.

31. Soltes GR, Schwalm J, Ricci DP1, Silhavy TJ (2016) The Activity of Escherichia coli Chaperone SurA Is Regulated by Conformational Changes Involving a Parvulin Domain. J Bacteriol 198: 921-929.

32. Skorek K, Raczkowska A, Dudek B, Miętka K, Guz-Regner K, et al. (2013) Regulatory protein OmpR influences the serum resistance of Yersinia enterocolitica $\mathrm{O}: 9$ by modifying the structure of the outer membrane. PLoS One 8: e79525.

33. Davies RL, MacCorquodale R, Caffrey B (2003) Diversity of avian Pasteurella multocida strains based on capsular PCR typing and variation of the OmpA and OmpH outer membrane proteins. Vet Microbiol 91: 169 182. 